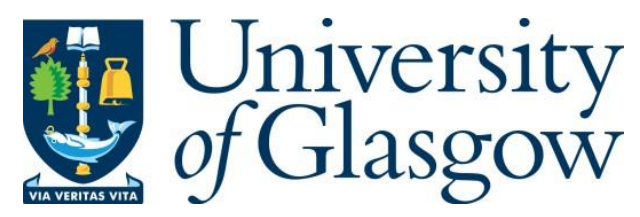

Jamieson, M., Jack, R., O'Neill, B., Cullen, B., Lennon, M., Brewster, S. and Evans, J. (2020) Technology to encourage meaningful activities following brain injury. Disability and Rehabilitation: Assistive Technology, 15(4), pp. 453-466.

There may be differences between this version and the published version. You are advised to consult the publisher's version if you wish to cite from it.

\title{
http://eprints.gla.ac.uk/181811/
}

Deposited on: 19 March 2019

Enlighten - Research publications by members of the University of Glasgow http://eprints.gla.ac.uk 


\section{Technology to Encourage Meaningful Activities Following Brain Injury}

Matthew Jamieson ${ }^{1}$, Rachel Jack², Brian O’Neill', Breda Cullen ${ }^{1}$, Marilyn Lennon ${ }^{4}$, Stephen Brewster ${ }^{1}$ and Jonathan Evans ${ }^{1}$

Institute of Health and Wellbeing, University of Glasgow, Glasgow (1), Acquired Brain Injury Team, West Dunbartonshire, Scotland (2), The Disabilities Trust, Graham Anderson House, Glasgow(3), Department of Computing Science, University of Strathclyde, Glasgow (4)

Matthew.Jamieson@ glasgow.ac.uk 


\section{Technology to Encourage Meaningful Activities Following Brain Injury}

Cognitive and behavioural difficulties after acquired brain injury (ABI) may lead to reduced engagement in leisure and social activities. Increasing participation is a goal of neuropsychological rehabilitation and assistive and behaviour change technology can play an important role in this. Focus groups and interviews were conductive with brain injury rehabilitation stakeholders $(\mathrm{n}=24)$ : people with $\operatorname{ABI}(n=9)$, family members $(n=3)$ and care providers $(n=12)$ in order to understand the barriers to engaging in meaningful activities and what helps to overcome these barriers. A collaborative thematic analysis was performed by a multi-disciplinary research team using an approach based on Grounded Theory. Four central, interlinked, barriers were found; Access, Cognitive Difficulties, Anticipation (of Physical or Cognitive Difficulties) and Motivation. To overcome these barriers participants cited themes such as External Motivation from both Other People and Technology, Maintaining Momentum and different aspects of Being Planful. The results point to future directions for the purposeful development of effective assistive technology for this user group. Technology that is social, persuasive, adapts to individual needs and supports people to plan activities are likely to be particularly useful within neuropsychological rehabilitation.

Implications for Rehabilitation

- Adults with $\mathrm{ABI}$ and their carers describe problems accessing activities, cognitive difficulties, an-ticipation of physical or cognitive difficulties and low motivation as the key barriers to undertaking meaningful activities.

- Current solutions are external prompting, main-taining momentum and being planful.

- $\quad$ This detailed qualitative analysis of a diverse group of carers and service users allows insight into the assistive technologies that could aid rehabilitation.

Keywords: assistive technology; social participation; acquired brain injury; brain injury rehabilitation; qualitative

The authors declare no conflicts of interest. 


\section{Introduction}

Acquired brain injury (ABI) is highly prevalent in society and often leads to cognitive difficulties that can negatively impact independence and quality of life. ABI includes traumatic injuries to the brain arising from a head injury (e.g. road traffic accidents and falls), cardiovascular events (e.g. stroke), illnesses or diseases (e.g. brain tumour or encephalitis). In the United Kingdom, there were 348,934 hospital admissions for Acquired Brain Injury (ABI) between 2013-14 [1]. Memory impairments are highly prevalent after brain injury and common difficulties include disorganized thinking, problems with planning, language impairment, poor self-monitoring and difficulty switching between or initiating tasks [2]. These impairments make it difficult to live independently and perform everyday activities.

The PERMA model developed by Martin Seligman [3] describes the essential elements of lasting wellbeing; positive emotion, engagement in activities, positive relationships with others, meaning and accomplishment / achievement [3]. The lack of participation in meaningful and engaging activities is associated with reduced quality of life and can contribute to alcohol and drug dependency [4], [5]. The experience of participation has been described by people with $\mathrm{ABI}$ as including 5 categories; performing tasks, making decisions and exerting influence, being engaged in meaningful activities, doing things for others and belonging [6]. After acquired brain injury, people may find it difficult to participate in the meaningful activities they did prior to their injury [6] and they often experience the loss of social relationships [7]. Other research reported that people with ABI perceive that they are restricted in their ability to participate in society [8].

There are a multitude of factors that contribute to this lack of participation. For example, impaired cognitive abilities such as reduced executive and memory functioning may lead to poor initiation of enjoyed or meaningful activities, and may make it hard for people to plan ahead and to overcome the barriers to meaningful activities. It may be difficult for people with executive impairments to switch 
from one activity (e.g. watching TV) to another (e.g. painting) especially when forward planning and multiple steps are required (e.g. buying paints, finding and setting up their art supplies).

Neuropsychological rehabilitation aims to provide support, either by compensating for difficulties or training or retraining skills, to allow people to live independent, meaningful lives (this can be referred to as 'thriving' or 'flourishing'). In neuropsychological rehabilitation clinicians will try to identify and encourage the performance of activities which service users find enjoyable, which increase activity level, social participation and bring meaning to people's lives in a way which aligns with their values or character strengths. One key part of this is to reduce the barriers to actively initiating preferred activities during free time (e.g. the activity not coming to mind, not knowing how to go about setting up or doing the activity, or being distracted by other tasks). Neuropsychological rehabilitation is considered to be cost-effective [9]. However it requires intensive carer involvement over lengthy period of time to be effective [9], and it is most effective if there is a continuum of care between acute, in and out-patient settings [10].

There is a burgeoning field of research investigating assistive technology to compensate for cognitive impairments and researchers have noted the potential of technology to alleviate caregiver burden and optimise the involvement of care professionals [11]. This could also improve the continuity of care received over time [9]. Technology may help reduce the barriers to undertaking meaningful activities by prompting people to initiate meaningful leisure activities at the right time and in the right way and by encouraging their ongoing engagement in these activities. For example, prompting from technology such as a smartwatch or mobile phone can help people with poor task initiation after ABI to do tasks they otherwise would not do such as go for a walk [12], complete personal care [13], [14] and complete tasks of everyday living [15]. 
Clinical research in assistive technology for brain injury has tended to focus on compensating for distinct cognitive difficulties that impact life. For example, technology to prompt people to remind them about activities, and to guide them through the performance of activities. There is good evidence for assistive technologies that can support prospective memory by prompting people with ABI to do tasks at an intended time [16], [17]. Micro-prompting technologies such as GUIDE have been developed to guide people with executive impairment through tasks with multiple steps. O’Neill and colleagues showed that technology could guide people with ABI to perform tasks they had difficulty with in both inpatient and community settings and showed that the GUIDE micro-prompting system could support people with their daily routine as effectively as intensive support from rehabilitation workers [19]. Some research has also explored the use of technology that can offer combined prompting and organization support [20].

Recent advancements in computing research has illustrated that technology can do more than help organize and prompt to remind people of what they planned to do. For example technology can influence and encourage [21], connect people [22], help people form habits [23], and take charge of their healthcare [24]-[26]. Such persuasive and ubiquitous computing research has however rarely been applied to neuropsychological rehabilitation.

The success of both rehabilitation and the use of assistive technologies depends on a number of factors. Firstly, social and personal factors, for example younger age (in adults), less severe injury, higher premorbid intelligence, an absence of mental health difficulties and engagement with rehabilitation services all positively influence outcomes after brain injury [9], [27], [28]. Van Den Broek (2005) argues that, often, the reason rehabilitation fails to work is their readiness or acceptance of the rehabilitation process and their interactions with clinicians. This is no different when considering acceptance of assistive technology as a tool in rehabilitation. Resistance towards, or negative feelings about assistive technology including low trust or embarrassment when using have been identified as key 
reasons why people do not use assistive technology [29]. When considering the use of assistive technology in rehabilitation it is important to match technology with the individual [29]. Broadly speaking, uptake is most likely if there is encouragement and support in the rehabilitation environement, when the technology is usable and useful and when the person finds it acceptable [29], [30].

Given the importance of matching the individual to the technology, it is vital to understanding what personal and environmental factors influence the person when considering the design or implementation of assistive technologies. In this paper the possibility of technology supporting people to identify and undertake meaningful activities is considered. It is vital to gain a clear understanding of the personal and environmental factors that prevent or encourage people from performing meaningful activities in order to design technological solutions that meet user's needs. It is also important to understand the approaches commonly taken in neuropsychological rehabilitation to overcome these barriers, so technology can be designed that supplements these efforts.

This qualitative work describes an in-depth investigation of the barriers and solutions to the performance of meaningful activities for people receiving rehabilitation for brain injury. Focus group and interview participants $(n=24)$ were stakeholders in brain injury services (clinicians, carers, family members and service users). The findings inform insights into future research that can spark the development of assistive technology that is effective in brain injury rehabilitation.

\section{Methods}

This study involved 24 participants in four focus group discussions (9 people with ABI, 12 formal caregivers ( 9 were clinically trained care providers, 3 were carers without clinical training), 3 family members of somebody with ABI; 9 males and 15 females). Two focus groups and two one-to-one 
sessions involved people with a mild or moderate ABI and self-reported memory difficulties. Four focus groups were held with carers or family members of people with mild or moderate ABI with self-reported memory (see Table 1 for more details). No participant took part in more than one session. The same questions were asked during the focus groups and one to one sessions. Participants were all over 18 (mean $=42$, range $=26$ to 62 ) and were able to speak fluent English. Only people able to provide informed consent without severe physical or sensory disability were included. All participants with ABI were adults (mean age $=48$, range $=40$ to 61 ) and none described themselves as experts with technology. All participant's ethnicity was White, British or White, Scottish. Using the age cut-offs of 18-29, 30-64, and 65+, there were 0 younger adults, 8 adults and 1 older adult with ABI. In the total sample there were 3 younger adults, 16 adults, and 3 older adults.

Therefore this group is relatively homogenous in age, ability to use assistive technology and ABI severity.

[Table 1 about here] 


\section{Focus group and interview session structure}

Focus group methodology was used in order to build up a rich qualitative dataset. One-to-one sessions were required to supplement the focus group sessions because three people with $\mathrm{ABI}$ did want to take part in the study, but did not feel comfortable speaking in a group session. The structure of the study session was the same for all focus groups and one-to-one sessions. The sessions lasted around one hour and were audio recorded. Two experimenters (MJ and RJ) were present during sessions 1, 2 and 4 in order to establish a sound approach and methodology (the second researcher noted timings etc that could be used in further sessions) and one was present (MJ) during the others.

The study sessions comprised of a discussion:

A) Identifying activities that bring meaning that people previously did, currently do, or would like to do more in the future;

B) Discussing the barriers to undertaking or pursuing these activities.

C) A discussion about the solutions people have used or might use to overcome these barriers.

No assistive technologies were provided to participants as part of this study. The interviewers described assistive technology when introducing the focus group and the participants were invited to think about assistive technology for helping overcome some of the solutions to the barriers to undertaking meaningful activities after a brain injury. During the sessions the interviewers picked up on the meaningful activities and difficulties described as a probe to prompt the participants to think about where technology might help, and to draw on their experiences using technology in the past.

\section{Data Collection and Analysis}

Six experimenters who had experience with working with people with $\mathrm{ABI}$ and / or experience in the field of assistive technology and HCI took part in the qualitative analysis of all of the study sessions. Each focus group was transcribed verbatim and the main author organized the data into comments, 
quotes, interactions, observations or written feedback using the guidelines for focus group analysis in health research described by Rabiee [25]. The data were coded using thematic analysis based in Grounded theory [26]. Glaser's definition of Grounded Theory was used; 'Grounded Theory is simply the discovery of emerging patterns in data. Grounded Theory is the generation of theories from data' [31]. The method of research used is Grounded Theory because we began with broad questions in order to inductively develop an understanding of the barriers and solutions to undertaking meaningful activity, coding our results between the focus group sessions.

\section{Data preparation}

The data was prepared for analysis using the framework approach. This approach was followed because it allowed the large quantity of transcript to be reduced and organised prior to thematic analysis. The approach used was outlined by Rabiee [32] and recommends eight key steps during data interpretation (words, context, internal consistency, frequency, intensity of comments, specificity or responses, extensiveness and big picture), was followed as closely as possible. This framework approach was ideal because it was developed to be used in health based focus group analyses. Data were then printed out onto sticky notes and colour coordinated according to the focus group topic or question the participants were addressing during their comments (e.g. blue post-it notes for carer group comments and yellow post-it notes for ABI group comments). This allowed the experimenters to keep the context of the comments in mind while organizing the data into themes.

\section{Thematic Analysis}

Thematic analysis, based in grounded theory, was desirable because no prior theoretical framework informed the analysis. The data were coded with close reference to the verbatim transcript of the focus group in order to give due consideration to the intended meanings of the words used (e.g. where there might be double meanings or local expressions) and the intensity of the comments made (e.g. emotional 
weight of comments or positive and negative terms used). The frequency and level of depth of the comments were noted and participant's internal consistency was kept in mind. It is recommended that coding be performed while data collection is taking place, with the thematic analysis feeding back into future focus groups. Finally, it is recommended that time is taken between coding sessions for experimenters to reflect on the larger issues which emerge from an accumulation of evidence (the big picture). These two recommendations were followed by having seven separate focus groups over several weeks with six group coding sessions (between focus groups 1 and 2, 2 and 3, 3 and 4, 4 and 5, 5 and 6, with a final session after the $7^{\text {th }}$ focus group and two one-to-one sessions were completed). Coding sessions involved six contributors (the authors of this paper) collaboratively interpreting the data. At least three of the coders were involved in each coding session. Three (MJ, MML and SB) have expertise in human computer interaction research including assistive technology and four have expertise in neuropsychological rehabilitation including technology based interventions (MJ, BC, RJ, JE). Where the discrepancy of opinion could not be resolved after a debate a consensus was reached to decide which theme the data should be coded to. Themes were named by the experimenters to define and summarize the ideas expressed by participants as accurately as possible. During this coding process that the overarching themes outlined in the results emerged.

\section{Results}

\section{Examples of 'Meaningful Activities'}

Participants with acquired brain injury initially found it difficult to come up with meaningful activities that they enjoyed or wanted to undertake more often. For example James, a 60 year old man with a TBI said,

“That's em... That's 'I don't do leisure activities' - I am the quintessential lazy bee...I get up in the morning and turn on the TV and then I go to bed." 
However, as the sessions progressed, all groups were able to give examples of activities that brought meaning to them or the people they care for. Examples included going to support group meeting, swimming, cooking, going to the pub, cycling, gardening, hiking, playing football, attending the gym, Writing, going to the museum, playing computer games, running errands and voluntary vocational activities. It was clear that what is meant by meaningful activity varies a great deal from person to person. Brain injury is a life changing event and so what constitutes a meaningful activity may also depend on their level of disability, their rehabilitation, mental health difficulties associated with their brain injury and their re-emergence into the social sphere [33]. This was well expressed by Fergus, a man with TBI who reported that he suffered from depression,

"You know we need to dial back a little bit on the em... ideas of activities and events to be; 'go outside the front door. '“

\section{BARRIERS}

In the first part of the discussion the experimenters used the examples of meaningful activities given by the participants to initiate a discussion of the barriers to undertaking these activities. Table 2 outlines the main themes and sub-themes from the thematic analysis of the transcripts from this discussion.

[Table 2 about here]

Access

Many participants mentioned issues with access to different events such as problems with travel, distances involved and the cost of activities. This is a particular problem for people with brain injury as they are often unable to drive or work which makes it difficult to travel independently and means they do not have expendable income to spend on hobbies. Some participants also mentioned physical disabilities that prevent them from doing activities that they used to enjoy. They also mentioned the 
issue of becoming fatigued and problems with overexerting. Jennifer, a woman with a number of physical as well as cognitive impairments that were a result of her brain injury discussed this;

"I would say... another thing is... the fatigue. If I have a burst of enthusiasm and do something energetic, the impact after is (awful). So much, worse or different than, maybe, other people... so I find that the rest of the day I'm kind of incapacitated. If I have a burst of activity... a burst of using eh... energy and stuff that afterwards I'm absolutely shattered. It kind of impacts on the rest of the day depending on how far I walk or how much I do-depends on what I'm limited to do later on."

Such mental and physical fatigue was commonly reported by participants with ABI and clinicians. This makes establishing activities that bring meaning particularly challenging because they tend to be prioritized lower than rehabilitation activities such as physiotherapy and neuro-rehabilitation sessions which can take up all of their energy. There is also the issue that cognitive impairment can mean that people fail to judge their limits and overexert themselves.

Another sub-theme of access was accessing solutions; being unable to access the services that could help people attend desired activities. This sub-theme mainly included comments about accessing rehabilitation and having carers or family members that could help support the performance of activities. Sarah, an occupational therapist who works in a rehabilitation centre summed this up;

"I guess it ties in to what kind of activity they're doing... many of our service users rely on support. You know there's perhaps limited activities they can do completely independently... It's so much dependent on how able they are."

As she continued it was clear that this was an issue for people that are more able to be physically independent as well as those that require more intensive support.

"Even the support to kind of get the initiation alone... to say, take someone to a hobby for the first time and show them what's available, support them to (do) it so that then they can make the step 
to initiate it independently thereafter. So even though some people are independent I think the financial burden and the burden of support is always there from the beginning."

\section{Cognition}

Various cognitive difficulties were described when participants discussed the barriers to participating in meaningful activities. Prospective memory was particularly important as people forget about their future intention and so are unable to carry out the activities they wished to do. Memory difficulties could often prevent people from doing the activity in the first place or being able to successfully carry out the activity. For example Catherine, a woman who recently suffered a severe ABI discussed her use of public transport;

"I got on a bus not that long ago and I couldn't remember the street I wanted to get off at - and you've got to tell the drivers... I went on one time and the bus driver was going through all the names of the streets. Like, I had one focal point, which was specsavers, and he's going through all the names of the streets and... I didn't... I couldn't make sense and I got... flustered and frustrated cos I couldn't say... 'no it's that one.,"

Difficulties with attention and executive functioning were also described by participants. This included distractibility where people find it easy to lose focus on the activity they are trying to do, difficulty with switching from one task to another (for example from watching TV to another activity) and an inability to initiate and perform new activites. For example, Lisa, a rehabilitation support worker discussed a man that wanted to read books. He was supported to attend the library but was unable to stay focused on the task;

"initiation alone is an issue and it's maybe even down to planning and their ability to plan the activity... they were picking books that just weren't suitable it was like, it was so impulsive, it was like a cookbook. Then...I was away 5 minutes and a support worker came to me and says such and 
such (service user) is looking for you em he's got the book he says that you were coming to take it off him. So he was completely confused by the situation."

Executive difficulties can also result in poor planning and organisation in advance of the activity and / during activity itself. The occupational therapists discussed supporting this process;

"The guys that would kind of go to things here as well - we put it on their timetable so they know when to go... but when they are home they've got to factor into their day travel time, how do I get there? Do I need some... do I get the bus, am I going to need to get a taxi? It's... I suppose it's the planning skills, sequencing and organising tasks as well."

Difficulties with social cognition and behavioural difficulties are other important barriers to people actually carrying out and enjoying activities that involve other people. Both the social cognition of the service user and that of other service users were discussed. People with ABI often associate with other service users through support groups and rehabilitation facilities. This was mentioned by Tom, a clinician working in a community treatment centre discussed dealing with social dynamics when running a boules group;

"Maybe, maybe getting some ground rules down before you, before you start an activity (is important). Because that was a nightmare that day ... you can see people getting frustrated and a bit annoyed (with each other)."

\section{Anticipation}

Importantly, it was not always the experience of accessibility issues or cognitive disabilities that actually prevented people from pursuing the activities they discussed. The anticipation of these problems, based on past experience or due to difficulties with anxiety was an important barrier.

For example, as described in the access theme, Jennifer discussed her fatigue and burn out. However she also talked about her fear of burn-out negatively influencing her performance of meaningful activities; 
"(Fatigue) impacts on the rest of the day depending on how far I walk or how much I do - depends on what I'm limited to do later on. Which... it's kind of... it's demoralising. It kind of puts you off doing anything in the first place!"

Clinicians described times when clients had been reluctant to try activities due to fears of negative social evaluation. For example, Audrey, a rehabilitation specialist working in a live-in centre and other staff mentioned this.

"we've got people in here have major social anxieties... and sort of going to an actual social event just puts them off. They prefer maybe carrying things out on a one-to-one basis. Then you've got the people that then do enjoy the social aspects, it's completely split."

Anticipation of cognitive difficulties were also mentioned. For example, Catherine who discussed her

memory difficulties when travelling to activities identified the anticipation of these difficulties as a major influence on her decision to do it;

"Like sometimes when you get on and off buses and that you forget where you were going. I mean ... and... it stops you from going out because you're scared of getting lost..."

This anticipation of negative consequences impacts motivation. Rehabilitation professionals can encourage people and make an activity accessible and enjoyable for an individual, but this has limited impact if a client is not willing to do an activity in the first place. This theme is therefore highly interlinked with motivation, discussed below.

\section{Motivation}

A number of participants talked about just not wanting too or not being bothered without giving specific reasons why this might be. Others stated that they had difficulty starting even when opportunity presents itself, and often made several excuses that, on reflection were not good reasons. Some mentioned 
difficulties managing priorities which links to planning and organisation difficulties notes in the Cognitive Difficulties theme.

Mental state and mental health was mentioned by some participants. One participant with ABI discussed his difficulties with depression. Another spoke about their social anxiety. Even in the absence of specific mental disorders, mental state and mood was identified by clinicians, family members as influential to participation. Both internal and external factors can influence this, for example the, as Jennifer noted;

'I think it's very easy in colder months to go, 'no, no, it's dark, its...' the weather's rubbish, 'I'll just stay in, I'm not going to bother. ,’

Another key aspect of motivation is finding activities that somebody enjoyed and will be motivated to do. Clinicians noted that, often, the activities they suggested for their clients were not the ones they wanted to do. While the clinical teams were accommodating to the clients, if they had a history of drug and alcohol addiction then some activities had to be avoided to reduce risk of relapse. This can often be a source of conflict in brain injury rehabilitation. Entering rehabilitation can result in a huge lifestyle alteration and so it can be difficult for some people to know where to begin. Lisa made this point when she said;

“... a lot of our service users... they don't actually know what they enjoy. Cos they've maybe had lifestyles that have been quite chaotic in the past and substance misusers and alcohol(ics). So when they come here it's not that they lack initiation to get involved in activities, it's that they don't know what activities to get involved in."

Another key aspect of motivation that participants discussed was reduced motivation due to losing momentum with activities that had been started, but for some reason had stopped. For example Daniel, a practitioner in a community treatment centre discussed a regular group activity that lost momentum; 
“...because it stopped over Christmas they never started back up until the end of January, trying to get these guys back in that momentum, do you know what I mean, was incredibly difficult."

This was mentioned often by clinical teams. Initiating activities for clients is a challenging task, especially when working with people with cognitive difficulties who find it difficult to initiate and plan activities. They also report that a large amount of their effort goes towards planning and encouraging activities that people regularly do in order to keep momentum with these activities and support the service users to keep independently organizing them.

\section{SOLUTIONS}

Participants were also asked to talk about what had been used to overcome these barriers in the past, and what they thought might help overcome the barriers in the future. Table 3 gives an outline of the themes and sub-themes that arose from this discussion. The problem / solution cycle theme is kept separate from the main barrier and solution themes because it describes the process of identifying barriers and solutions within rehabilitation, as well as describing specific barriers and solutions.

[Table 3 about here]

\section{External Motivation}

A major theme when discussing solutions to the barriers to pursuing meaningful activities was having some form of external motivation. This often comes from other people either through social obligation, or social and emotional support. External prompting was a very common solution, usually describes as a way to help people overcome poor initiation, memory difficulties. The most common method of external prompting was from other people. Fergus, talking in one of the ABI focus groups discussed the importance of other people;

"Um... but being reminded about something isn't enough for me... you know... I think motivation comes from other people." 
Other participants mentioned different approaches that could be taken by trusted others (clinicians or family members) to motivate action. For example Tom and Lesley, community based carers discussed using rewards such as positive feedback or anticipation of positive feedback to increase motivation to do outdoor activities and get active;

\section{Lesley:}

“(When cycling) on different roads you're actually competing against other people for who does it quickest, other people that use the app. So the likes of (service user), that's the kind of thing that would motivate him on his bike I think, something like that."

\section{Tom:}

"Yes, uh hu. And something like that might help in a group, 'look guys, you have all got a smartphone, right here we are, that's something, box of sweeties, everyone chips in and there's a box of sweeties for the $1^{\text {st }}$ person that gets to the first quarter. Something, you know what I mean, something to kind of make it fun. Bit of competition but healthy competition.."

Another approach was tying activities to values, working with individuals to come up with activities they will enjoy. Amanda, Lisa, and Cathy, who are clinicians at a rehabilitation centre discussed this;

Lisa:

“I mean we've got a few service users in here now that would absolutely not go and they've said blank like they would not go to activities like group activities, anything that's social. I think it depends on what the individual is seeking in a..."

\section{Cathy:}

“You just can't generalise can you?"

Lisa: 
"Yeah it's so difficult. I think it is good for because we've got people at each end of the scale.

We've got people in here that are really socially anxious and they would not consider... and then we've got the opposite... ah they're quite confident really."

An important part of this motivating process is using 'social contract' to encourage initiation of activities. For example a family carer mentioned the fact that his daughter is much more likely to leave the house when a friend comes to get her than when he prompts her, possibly because she feels too comfortable around him, or because he is easier for her to say no to. Clinical staff were quick to note that these motivation techniques, particularly using feelings of social motivation and reward had to be utilized with skill to create the right balance so people would not feel stressed or anxious. For example;

Lisa:

"If you do have somebody feeling uncomfortable then it's taking away the enjoyable aspect of the enjoyable activity really if someone really doesn't want to go to a group setting."

Amanda:

"Yeah and you can only judge that in the moment can't you? In the interaction."

A large part of the role of human caregiver motivation was prompting people to initiate, plan, or carry out activities and participants did acknowledge that technology could play a role in this. In one focus group with people with $\mathrm{ABI}$ there was a discussion of technology based prompting and technology as a means of connecting people to help with motivation and to support people to undertake meaningful activities. For example, they discussed technology that might enable them to plan specific tasks or events with others, and that might utilize feelings of social obligation, which can be helpful in some cases.

Fergus:

"So, so, so trying to involve an app that can be a link to involve other people is very important." 
Jennifer

"Mhm, uhu, yeah... I agree if you... put it out there that you want to..."

Catherine:

"It would simultaneously go off on other people's phone(s)."

Fergus:

"Yeah... that's an idea as well... if I said does anybody want to get a coffee then... um... if I was, if we had a group for example then everyone else's phone who's in the group would ping with a reminder... linking people”

James:

"That would be good..."

Technology that can increase motivation was also discussed. For example, Lesley and Tom discussed motivation that might be facilitated by a fitness app. Others discussed technologies that prompt about upcoming tasks, offer 'benign nagging' by giving someone repetitive prompting, use micro-prompting (guiding someone through the stages of a task with several steps, e.g. cooking), or which utilizes reward and feedback were also mentioned. It was generally the clinical staff who discussed the use of prompting technology as many of them had experience using this with clients. These discussions were not always positive (see problem solution cycle theme). However, occupational therapists working in a rehabilitation centre did discuss an important benefit of assistive technology as a more acceptable means of prompting than human caregivers. Jessica said;

"He didn't like when we prompted his self-care. He hated when his family prompted him. So his brother set up the messages and sent them. His brother would send the messages and change them every so often but he didn't know where they were coming from... so it took away that external pressure of a therapist telling you to do it, a support worker telling you to do it, a family member telling you to do it - it was just a reminder. That worked well because he'd come out and say, 'oh my phone told me to do this!,", 


\section{Maintaining Momentum}

Part of the motivation barrier theme was losing momentum, and participants talked about the importance of maintaining momentum as well as strategies that worked for them to help maintain momentum. Creating positive habits was an important strategy that could help maintain momentum and this was mentioned by a community care team in the fourth focus group and by the rehabilitation clinician in the fifth group;

Scott:

“(The) bowling group... (is) the same time every single week, the guys know that..."

\section{Stacy:}

“...if you've got them coming same time, same place then that builds up a good pattern, routine."

\section{Lisa (Rehabilitation Specialist, group 5)}

"I think for some people repetition does really help. And having a structure. And having it being like consistently on the same day at the same time because then they get used to that and they plan their week around that. And we've got service users that work really well with structures and having a set day for things but then... I don't know if that necessarily helps them attend. It just helps them be able to kind of view it and organise it within their life."

Another strategy was to push through initial feelings of doubt and discomfort. Sophie, a woman with ABI living in a rehabilitation centre, who had recently begun to leave the unit independently, expressed this well;

"Because em... I would say that the first time going out myself it was ah.... A bit overwhelming but the more you do it the more you get used to it."

Part of the role of clinicians and carers was to help people push past initial inertia and then help maintain repeated activities that are sustainable, with the hope that these will become self maintained in the future; 
Amanda (assistant psychologist, focus group 4):

"I mean they (service users) are anxious about it but do they really want to do it? Is it a goal for them? If it's not a goal for them and it makes them really anxious then, is it just that you find something - not completely avoid it and do nothing - but find something different that actually they want to do."

(Occupational Therapists, focus group 6)

Sarah:

"I suppose it's about... our duty of care is to show them that there are other things out there and see if they are interested in doing them. And then if we do find something they like it's trying to encourage that and see if they can get involved in things."

Jessica:

"It's like whether they continue with that once they do go home which is the thing..."

Sarah:

"Yeah and I think it's capacity - have they got the capacity to make that decision as well. If they want to go back to that (damaging previous behaviours or activities). Or if their brain injury is affecting their capacity... are they putting themselves at real risk if they go back? So we need to explore all those things..."

Maintaining momentum with participants requires prompting from others and so is highly linked with the external motivation theme. It is also linked to the next theme, being planful as even activities that are well established require planful behaviours in order to ensure they are able to be undertaken.

\section{Being Planful}

When discussing solutions, participants discussed several planning strategies that improved the chances of activities being undertaken. This included coming up with specific plans or implementation 
intentions, and using planful strategies to help overcome memory difficulty that would prevent events from being undertaken were also mentioned.

As discussed in the external motivation theme, other people are very important in helping to motivate and prompt. When discussing planning strategies, participants mentioned the utility of 'collaboratively' planning;

Jessica:

“...you can... give them a sheet away that's got like Monday to Friday, or Monday to Sunday and then put in set things every week that they've got and encouraging them to fill in the banks."

Technology was also mentioned as a way of facilitating planning;

Lisa:

"We have a young service user who wanted to go for a walk but wasn't familiar with the area, wasn't great at planning so we sat down with them, done a google map plan."

Anticipation of cognitive or physical difficulties was mentioned as an important barrier. When this is the case having trusted others as a supportive back-up' to improve confidence was mentioned as a way to overcome this. For example Catherine mentioned that she would phone her mother if she became lost. To do this also required planful thought when organising activities, so that the trusted other is able to be there as a back up.

\section{Problem Solution Cycle}

The focus group discussions were not a linear discussion of the barriers followed by the solutions. Discussions often moved from talking about solutions that would then lead participants to think about other barriers. In some cases the solutions implemented in rehabilitation created new, or uncovered other, barriers that then needed to be addressed. This was sometimes seen as frustrating, but also as a necessary aspect of the challenging process of brain injury rehabilitation.

While many of the solutions mentioned by participants had a social element, the negative aspects of social expectation were also discussed; solutions that hinder as well as help. For example clinicians 
noted that people can feel stressed or anxious when put into social situation and may feel under pressure to do social activities. This can be encouraging but also may put people off doing activities in the future if it is not managed carefully. This was expressed by Lisa when she said that feeling uncomfortable might take away from the enjoyment of activities (external motivation theme). In a one-to-one discussion with a woman who experienced communication difficulties after a severe brain injury, this topic of conflict about socializing arose;

Sally:

'I enjoy doing that (socializing). What I sometimes think I'm not good at is... and it's a two way process I suppose... I a week would go by and I'd go 'oh I meant to phone so and so!' or 'I should have contacted them!' Say you know to say let's get a cup of coffee or something. I'm not as motivated as I was to keep up the social contacts."

Experimenter $(M J)$ :

"And why is that do you think?"

Sally:

“Because it's harder work for me talking and being around people. But I still want to... I think I should... I think it's partly to do with the brain injury em... makes the two and fro of conversation quite hard. So people will speak to me and say something and I'll internalise it and then think of an answer, and way down the line I might think I want to say the answer now! But the conversation has moved on. So socially - where you may have banter or carry on, talking with friends, I'm not as good at... just saying what I think. So it looks like I'm not taking part but in fact I've heard what you've said and (know) what to say back."

Clinicians in a rehabilitation centre noted a difficulty specific to this rehabilitation environment. They are able to providing structure to someone's life and can be beneficial when encouraging people to do activities because there are many staff members around to prompt and encourage. It is also beneficial for 
being planful, creating habits and maintain momentum because schedules are consistent and written on a timetable that is given to participants daily. However when the person returns to the community this structure is no longer in place and this can disrupt or even put an end to the new behaviours and activities developed during rehabilitation. Lisa and Audrey discussed this and mentioned the dangers of people returning to a chaotic lifestyle after they leave rehabilitation;

Lisa

"Some service users, as much as they moan about timetables, see when it like Christmas time and we don't have a proper timetable for like two weeks, it's like all hell lets loose because people are just so used to a set structure. And that's one thing we worry about with people who maybe did have addictions in the past - that they're going to fall back into that because they are in such a rigid structure here and the go back home to no structure or very little."

Audrey

“...again I think that goes back to supporting people em... about possible difficulties with ABI. And how it almost becomes ritualistic.,,, The care vs control aspect (is important) too... The risksomeone might be wanting to participate in activity that they are seen as a risk... a high risk aspect of it. We... our staff would be discouraging that so then you would be then, you would be a barrier, we would be a barrier for some people to participate in certain things."

Another issue related to the problem solution cycle was the mention of perceived solutions that were inaccessible or did not work. A perceived solution failing to work can be seen as a new barrier. Rehabilitation teams and service users were often able to discuss new solutions that might work better. Many of the solutions mentioned by participants were actually inaccessible for various reasons. For example, some people mentioned that they did not have many other people that would prompt them, or that the people in their lives that could not support them to do activities they enjoyed. In the family focus 
group, Linda, a woman discussed difficulties finding social support for her husband after his brain injury;

"My husband had gone to a thing called the men-shed. With eh... my brother in law. And that's the that's the barrier for us - is em... he can't go on his own anywhere. So he's relying on em... like my brother in law - I couldn't take him to the men shed cos it's all men. So I'm relying on my brother in law to take him along. Now it was right up my husband's street, but it wasn't right up my brother in-law's street (meant figuratively). And to commit to doing that every week... I could just tell he wasn't really up for that. Em so the... I think the barriers for my husband participating in some things are just... he can't really be left to get on with it."

The community rehabilitation services noted the practical difficulties involved with externally motivating a large number of participants. When technology was discussed as a potential solution, barriers to this included cost, lack of availability, lack of expertise within clinical teams to use it and the fact that it didn't work in the past when it was implemented. For example, Laura, a clinical psychologist working a brain injury service discussed the use of prompting technology for one of their clients;

“And there's meant to be a phone reminder system which (service user) is meant to do a bit of and then we do a bit of, or Tom (occupational therapist) does a bit of. It feels that could be smarter in some way because if Tom is off or (service user) forgets to phone some people it kind of falls apart."

\section{Discussion}

The findings from the thematic analysis of discussions with a wide range of stakeholders in brain injury rehabilitation illuminate some key areas where assistive technology can be particularly useful to overcome barriers and provide as well as supplement current solutions. Given the importance of meaningful activities to brain injury rehabilitation, technologies developed to help people perform them 
will be valuable tools for neuropsychological rehabilitation. By reflecting on the findings and the current assistive technology literature four areas of focus for rehabilitation experts and technologists can be suggested. These are social technologies that link people with trusted others to improve support (social assistive technologes), persuasive technologies that motivate and encourage (persuasive assistive technology), technology with guidance and user interface design personalised to individuals' needs (personalised assistive technology) and technology that helps guide people through the process of planning activities (planning assistive technologies). These areas of focus for assistive technology developers are discussed below in relation to our findings and the current assistive technology literature. Table 4 provides a summary of this discussion with examples of technology that could help overcome the barriers, and provide the solutions, that were mentioned by our participants.

The participants with $\mathrm{ABI}$ in this study were adults, mostly in their 40s and 50s. Age may influence the acceptance of assistive technologies and the use of personal technologies. A survey of 81 people with $\mathrm{ABI}$ found that younger age and pre-morbid use of technology, and current use of non technological aids predicted $75.8 \%$ of current technology aid use [34]. Participants were selected from community care, charity support groups and inpatient rehabilitation in order to give a balanced overview of the issues for people within different services. There were differences in the topics discussed by groups in different rehabilitation types, which is unsurprising considering the influence of personal and environmental factors on outcomes [27], [28] and utilization of assistive technology [29]. For example, the staff and service users in the inpatient rehabilitation centre discussed the structured schedule and environment and both is benefits to support people and difficulties when this structure is removed again when the individual returns to the community. This issues was not discussed in the same depth by clinicians or service users in the community or charity service. Severity of injury also influenced the feedback given. For example, service users recruited in the rehabilitation centre (Sophie and Mitchell) were both more 
severely impaired following their injuries than those in community care and required more support in order to undertake the meaningful activities they described.

[Table 4 about here]

\section{Social assistive technology}

The discussion by brain injury rehabilitation stakeholders highlighted the central role of significant, trusted others (family members, friends, clinicians) in encouraging people to undertake meaningful activities. The most commonly discussed solution was external prompting and motivation, particularly from other people. Trusted others are of key importance not only in providing prompting, but encouraging, providing structure and supporting the performance of activities. Furthermore, overcoming access difficulties, finding the confidence to overcome fearful anticipation, and the processes of being planful and maintaining momentum all often involve help from carers and family members. However, the assistive technology that has been investigated in a neuropsychological rehabilitation context tends to be personally, rather than socially, oriented. For example, the prompting technologies that have been trialed to improve everyday memory performance were all software on personal devices on which the participant's schedule was entered [16]. The schedules were not linked to those of friends or family members.

It is social technologies that motivate and best capture attention and interest; as useful as a scheduling app or goal setting app might be, you are not going to engage with it as much as Facebook or Whatsapp. Research on interruption has shown that push prompts that interfere with ongoing tasks were tolerated, even positively received when the prompt conveyed social information [35]. Social technology, including social media, has been investigated for brain injury rehabilitation of young people [22]. Bedell and colleagues [36] have taken initial steps in the design of a coaching app that helps teenagers with 
ABI with social engagement. A focus on developing technologies that connect people with ABI could be valuable at any age; especially considering the low number of social contacts people with ABI have [7] and the increasing use of personal technology by older people [37]. In the Matching Person and Technology framework, little or no support for use from family or peers is an important factor associated with non-use [29]. Another key factor related to the technology is that preferred options are available. Compared to other solutions discussed, the participants made double the number of comments about prompting from other people as a solution. This indicates a preference for prompting that involves other people. Assistive technology that is able to utilize this preference is likely to be more successful than technology that tries to compete with prompting from other people.

\section{Social re-emergence}

A recent paper by Feuston et al. [33] described social re-emergence that people undergo after a brain injury. This process involves the development of a new social identity over time and can include social withdrawal post-injury. This was touched upon by participants in this study when discussing performance of meaningful activities. Meaning is often achieved through participation in social events and connection with others. Barriers included finding leaving the house and undertaking new activities anxiety provoking, with some expressing fearful anticipation. Rehabilitation staff appreciate the complex challenges involved in helping people engage socially during brain injury rehabilitation. It is important that technologies are developed to support this process.

\section{Designing to persuade and motivate}

It is interesting to note that while a lack of personal motivation was a key barrier to performing activities, the opposite of this - drive and passion for hobbies or activities - was rarely mentioned as a solution. Instead of internal motivation, external motivation is seen by stakeholders as a key driving force in brain injury rehabilitation. This suggests that people with ABI heavily rely on carers and family 
members to provide motivation externally. Carers use prompting to do this but also help to generate ideas, use encouragement and persuasion techniques to motivate, help to plan and guide people through tasks and establish constructive habitual behaviours. Technology also has the potential to motivate and persuade, and the growing field of persuasive technology can be applied to neuropsychological rehabilitation.

\section{Internal/intrinsic motivation}

Technology based supports could not only help to provide the external prompting and motivation so key to the performance of meaningful activities, they could also help people to regain or develop internal motivation. Technology has the ability to guide and support users while allowing them to retain a sense of ownership of their ideas and mastery of their performance. Satellite navigation systems in cars or on Google Maps on phones are good examples of this. They are tools we use every day that provide guidance but, compared to receiving human help with the same tasks, still allow us to retain a sense of mastery. For example you might feel you navigated successfully to a friend's house using sat-nav. It is likely that if a 'back-seat driver' provided the same guidance you would not have the same internalization of your navigation abilities. This advantage of technologies could be applied to rehabilitation to foster feelings of intrinsic motivation even when prompts and guidance are necessary to help people develop ideas for activities, plan and perform them. This process was described by Jessica, an occupational therapist at an in-patent rehabilitation centre, who discussed her patient who found prompts from his phone much more acceptable than when the same prompts were from his caregivers. Delivering neuropsychological rehabilitation can be particularly challenging in cases where somebody does not have full awareness of their deficit and does not accept that they need help. Indeed, the introduction of interventions before the client has accepted the need for care has been documented as one of the key reasons for failure of rehabilitation [38]. A client in this position may respond negatively 
to prompts from therapists; verbal prompting is a quite common antecedent to aggressive behaviour [39]. In these cases the assistive technology may be very useful because it can deliver prompts that are not perceived as being from another and therefore increase feelings of autonomy whilst supporting the user with their needs. One example of this is the GUIDE system that can deliver personalised prompts to help people with their morning routine. This system supports the individual to perform their morning routine with the same effectiveness as a human caregiver and removes the need for a carer to come into the service users room in the morning to deliver prompts, an action that can be perceived as intrusive (O'Neill et al., 2013).

\section{Idea generation}

For people with poor initiation and apathy following ABI, contemplation of intended activities might not be possible because the ideas do not occur to them. Similarly it might be that people do not begin contemplation, planning and preparing without external prompting, a key theme throughout the focus group sessions. Indeed some of the clinicians stated that even activities which were carried out regularly often required quite deliberate prompting from others (e.g. picking people up to take them to events or prompting the night before and day of the event). Such a high level of support is unsustainable when transitioning from in-patient to community care. Furthermore, the role of staff providing care within rehabilitation can be complex especially when their duty of care conflicts with the desires of patients. If service users feel like their lives are being restricted then they may be unlikely to accept suggestions of activities from clinical staff.

Assistive technology could play a role in supporting the service user's idea generation, and the selfefficacy associated with that idea. Technology has the dual advantage of not being another person and being personal to the user. As such, these technologies can be used in both in-patient and community setting. Furthermore, suggestion from technology delivered on a personal device might be more 
persuasive than staff, especially if the staff denied an activity suggested by the patient. In this case the role of the staff members transforms from deniers of a desired activity, who suggest alternatives to facilitators of desired activities.

\section{Habit Formation}

Structure has a hugely important role in supporting people, especially if they have previously lived chaotic lives. However structure is not always a good thing because it can cause ridgid thinking and when it's taken away it can cause people to fall back into old patterns. Habit formation using persuasive technology could be very helpful here. If everyday technologies can be used in a consistent way to structure activities and help people establish patterns of behaviour then this might reduce the negative impact of moving from a highly structured environment to a less structured one.

One way to do this is to attempt to foster habitual use of the technology. Stawarz and colleagues [23] developed a medication reminding system that used event based prompts instead of time based prompts that are more common for reminding systems. Event based prompts may be more effective when attempting to develop scheduling behaviour as a habit (e.g. setting your daily schedule each morning after breakfast). Other researchers have developed frameworks for designing for habit formation. For example Fogg et al. [40] developed a framework for persuasive design based on the central aspects of habit formation; motivation, ability to perform the desired behaviour and the trigger or antecedent of this behaviour. This kind of behaviour change theory has recently been applied to brain injury rehabilitation [41], [42]. There is scope for theories of persuasive technology to be used to inform the development of assistive technology for use in neuropsychological rehabilitation.

\section{Personalisation}

The importance of creating software that can adapt the support provided to individual's needs is clear when looking at the range of meaningful activities described by our participants. Clearly different 
support and guidance is going to be required when planning a hike compared to when undertaking a voluntary vocation, or going to the local sports centre. Furthermore, the needs of individuals varies hugely depending on their physical and mental health, as well as their cognitive abilities.

\section{Personalised prompts and plans}

It would benefit patients using assistive technology to have personalized prompts, plans and rehabilitation strategies. This is an important part of clinical neuropsychology; clinicians work closely with their clients to provide personalized care plans. It is possible for technology used during rehabilitation to also be personalized. For example, clinicians may set a schedule with a client on a smartphone calendar to give people relevant and timely prompts to remind them to do activities. Despite the fact that this technology currently exists, rehabilitation teams often reported that it did not work as intended. Two ways to improve the effectiveness of prompting and planning technology may be to apply research into Just In Time Adaptive Interventions [43] which may be able to capitalize on advancements in information science to develop software that responds to individuals' needs [29], [44].

Technologies that prompt to help the user complete tasks are likely to be most effective if they are received near the moment of the decision being made (Just-In-Time interventions) [45]. Even better are messages personalised to the individual or adapted the current situation (Just In Time Adaptive Interventions) [43]. For example, technology could adaptively prompt people with substance abuse problems; input from the user and environment is used to assess risk. If the risk is low then the prompt is an encouraging message and if it is high then an intervention is recommended. Examples of interventions that can be included in a Just in Time Adaptive Intervention are tangible resources for problem solving [46], that encourage and enhancing self-worth [47], that facilitate support from others [48], [49], or even provide support from others without the need for the user to seek for help [50], [51]. This approach has become more feasible in recent years with advances in situational modelling, sensing 
technologies and because of the ubiquity of personal technologies that are able to collect large amounts of data about their users [43]. There is increasing interest in the use of sensing technologies to deliver adaptive interventions in brain injury rehabilitation [11].

\section{Accessibility requirements}

If those providing rehabilitation want to increase the use of assistive technology then technology should be as accessible as possible for each individual. Human Computer Interaction researchers have developed web interface design guidelines for people with cognitive impairment. For example, many W3C guidelines are relevant such as ensuring users have enough time to understand and use the content, making navigation clear (e.g. clear titles and headings), making sure text is understandable and helping the users avoid and correct mistakes (Web Accessibility Guidelines). The cognitive impairments that can occur after head injury may give rise to different accessibility requirements for assistive technologies [52]. Research has been carried out with people with different types of impairment such as developmental difficulties [53], ABI [54] and dementia [55]. Two influential papers have listed the top four recommendations synthesised from the literature. Friedman and Bryen [56] collated the most common web recommendations for designing for people with cognitive impairments. Four recommendations cited in the papers, were 1) to use pictures, graphics, icons, and symbols along with the text, 2) use clear and simple text, 3) use consistent navigation and design on every page and 4) use headings, titles, and prompts. Freeman et al. [55] developed very similar guidelines for people with dementia and additional recommendations are to use colour and contrast cues to direct the user around the website and to minimize the number of choices on each page.

These guidelines can influence the design choices when creating assistive technologies. For example, if there is a need to minimize the amount of information presented on a small screen a narrow / deep user interface design (lots of screens each with less information) might be preferable to a broad / shallow 
approach (with few screens each with a lot of information) [57]. There is evidence that narrow / deep UI might be preferable in web search interfaces [58] and scheduling applications [59]. Another design choice is how pro-active a piece of software is in attempting to grab the users attention. Unsolicited push-notification prompts can be annoying, but also helpful if people have apathy or poor selfmonitoring, common after neurological injury. Unsolicited prompts to use a reminding app were investigated in a neurpsychological rehabilitation centre [60]. Participants set many more reminders when receiving these prompts. These examples illustrate the potential impact of theory-based design to improve the accessibility of assistive technologies.

\section{Planning}

Being planful included 'coming up with specific plans' (implementation intentions), 'using memory strategies' to overcome memory impairment, 'collaboratively' planning with other people, and having 'other people as a supporting back-up' to improve confidence could be vital for people with ABI to progress through the steps. Good forward planning and strategies could help to overcome many of the barriers specific to the individual with cognitive impairment.

Assistive technology can play a key role by providing a platform for constructive planning behaviour. It can supplement a central aspect of neuropsychological rehabilitation; setting personalised goals and helping patients achieve them. For example, if someone has prospective memory difficulties they may forget about upcoming intentions and also worry that they will forget where they were getting off on a bus journey to somewhere they have never been before. In this case a prompt from a phone about the event might mean that they remember the event, but it would not be enough to allow them to overcome the barrier of anticipating difficulties. They may also need someone they trust to available via a phone call (and perhaps also have GPS tracking) to give them the confidence to go somewhere new. 


\section{Design with Neuro-Rehabilitation in mind}

The solution problem cycle theme illustrated that potential solutions using technology are not always successfully implemented and can result in the opposite to the desired effect. This highlights the importance of working closely with stakeholders to develop technologies that can help overcome existing barriers and facilitate existing solutions. Furthermore, considering that a central theme when discussing solutions was social support, it is important that technology is not seen as, or does not become, a means of replacing human caregivers. Rather it can allow people to provide better care by assistive with repetitive tasks (like everyday reminding), and improving logistics (by linking people during planning and performance of activities). It may also be of use in circumstances where human caregivers have the disadvantage of appearing intruding or nagging. Furthermore, the increasingly pervasive and deeply personal presence of technology in our lives could be harnessed to increase intrinsic motivation for performance of activities.

The structure of neuropsychological rehabilitation presents difficulties for clinicians and service users. Highly intensive post-acute care (e.g. live-in rehabilitation units with specialist, multi-disciplinary care staff) is expensive to maintain and community care is not able to provide this level of care. This can result in people returning to their previously chaotic lives and undesirable habits, and results in a readmission to costly intensive rehabilitation. Many of the participants working in clinical services described this difficulty. Technology that supports rehabilitation has the advantage of being the same regardless of the level of care. Future work introducing assistive technology for this group could focus on the identification of appropriate technological supports for service users in intensive rehabilitation. This would allow the service users to be trained with technologies while the support is available, and then use those skills to continue utilising the assistive technology when living in the community. This is already a practice described by clinicians; better technologies would improve their ability to provide effective assistive technology and improve care outcomes. 


\section{Implications for Rehabilitation and Future Research}

The four focus areas outlined in table 4 are insights that may help clinicians and researchers consider the deliver and development of assistive technologies to support people to undertake meaningful activities. These findings have implications for rehabilitation because they highlight the issues currently facing staff, carers, family members and service users and highlight some of the solutions currently used. This can, in turn, help guide the development and/or deployment of assistive technologies that can overcome these barriers and supplement current solutions.

\section{Social}

The findings from this study highlight the potential utility of social technology not only as a tool to connect people, but to overcome many of the barriers clinical neuropsychology staff are faced with everyday. Technologies that link people to friends and family could make it quick and easy for others to offer motivation, could reduce people's fearful anticipation by facilitating carers to provide 'back-up' support remotely (e.g. be available to call if someone gets lost), and improve access to activities by linking patients' and carers' schedules to facilitate joint planning. Focusing on social technology could make it easy for caregivers to provide external motivation (e.g. remotely).

\section{Persuasive}

This work highlights the potential for motivating through prompting and guidance using technology, helping people form habits and generate ideas. Future research could investigate what kinds of messages are most for different tasks and difference individuals. Studies could also investigate if it is feasible to use assistive technology to help people generate ideas for meaningful activities or form positive habits to help their rehabilitation.

\section{Personal}

Many of the participants found that technologies they had previously used did not meet their individual needs. Technologies that are matched to the user [29], are able to send adaptive support depending on 
the environment [43], and that are designed to be accessible [56] may be more likely to be successful. Future studies could involve the development and deployment of technology based interventions combining these components.

Planning Technology that allows specific plans to be made by the person who intends to carry them out may be very useful because the process of creating a plan can lead to behaviour change. There is a large literature on the impact of implementation intentions on follow through of intended behaviours [61]. Technology that facilitates the specific planning of events ('when Y happens I will do X') is likely to be effective [62]. Developing accessible technologies that help people to plan and schedule independently is a key part of this. People with ABI who used scheduling software to set their own reminders reported memory benefits came from the process of setting reminders as well as from receiving the timely prompts [60].

\section{Conclusion}

This work contributes to the literature by providing a detailed description of the issues that impact a crucial aspect of brain injury rehabilitation; participation in meaningful activities. The work is particularly valuable as the methods allow us to examine the results through the lens of assistive technology development. The aim was not only to describe the issues impacting the ability of patients to live a meaningful life, but also to apply these findings to identify the areas of focus for assistive technology researchers.

This qualitative research outlines major themes that prevent and facilitate the performance of meaningful activities for people with brain injury. The motivation was to inform the development of assistive technologies that can effectively support people, and fit into the services that currently support them. Solutions are required to overcome difficulty with access to activities, cognitive impairments, anticipation of difficulties and low motivation. Solutions already used in neurpsychological 
rehabilitation include external prompting from others, being planful and maintaining momentum and technology should be developed that improves the delivery and impact of current solutions. The findings

illuminate key areas of focus; social, persuasive, personal and planning technologies. It is important that this research is multi-disciplinary bringing computing scientists together with clinicians.

\section{References}

[1] Headway, "Brain Injury Statistics," 2015. .

[2] J. J. Evans, B. a Wilson, P. Needham, and S. Brentnall, "Who makes good use of memory aids? Results of a survey of people with acquired brain injury.," J. Int. Neuropsychol. Soc., vol. 9, no. 6, pp. 925-35, Sep. 2003.

[3] M. Seligman, Learned optimism: How to change your mind and your life. Vintage: USA, 2011.

[4] S. E. Iso-Ahola and E. D. Crowley, “Adolescent substance abuse and leisure boredom," J. Leis. Res., vol. 23, no. 3, p. $260,1991$.

[5] L. L. Caldwell, "Leisure and health: Why is leisure therapeutic?," Br. J. Guid. Couns., vol. 33, no. 1, pp. 7-26, 2005.

[6] A. Häggström and M. L. Lund, "The complexity of participation in daily life: A qualitative study of the experiences of persons with acquired brain injury," J. Rehabil. Med., vol. 40, no. 2, pp. 89-95, 2008.

[7] J. M. Douglas, "Conceptualizing self and maintaining social connection following severe traumatic brain injury," Brain Inj., vol. 27, no. 1, pp. 60-74, 2013.

[8] M. Cardol, B. D. Jong, and C. D. Ward, “'On autonomy and participation in rehabilitation',” Disabil. Rehabil., vol. 24, no. 18, pp. 977-982, 2002.

[9] M. Oddy and S. Da Silva Ramos, "The clinical and cost-benefits of investing in neurobehavioural rehabilitation: A multi-centre study," Brain Inj., vol. 27, no. 13-14, pp. 1500-1507, 2013.

[10] A. D. Worthington, S. Matthews, Y. Melia, and M. Oddy, "Cost-benefits associated with social outcome from neurobehavioural rehabilitation," Brain Inj., vol. 20, no. 9, pp. 947-957, 2006.

[11] B. O'Neill and A. Gillespie, Assistive technology for cognition: A handbook for clinicians and developers. Psychology Press: UK, 2014.

[12] M. Jamieson, M. Monastra, G. Gillies, R. Manolov, B. Cullen, M. McGee-Lennon, S. Brewster, and J. Evans, “The use of a smartwatch as a prompting device for people with acquired brain injury: a single case experimental design study," Neuropsychol. Rehabil., vol. 0, no. 0, pp. 1-21, 2017.

[13] J. J. Evans, H. Emslie, and B. a Wilson, "External cueing systems in the rehabilitation of executive impairments of action.," J. Int. Neuropsychol. Soc., vol. 4, no. 4, pp. 399-408, Jul. 1998.

[14] J. Fish, T. Manly, and B. a Wilson, "Long-term compensatory treatment of organizational deficits in a patient with bilateral frontal lobe damage.," J. Int. Neuropsychol. Soc., vol. 14, no. 1, pp. 154-63, Jan. 2008. 
[15] B. a. Wilson, H. Emslie, K. Quirk, J. Evans, and P. Watson, "A randomized control trial to evaluate a paging system for people with traumatic brain injury,” Brain Inj., vol. 19, no. 11, pp. 891-894, Jan. 2005.

[16] M. Jamieson, B. Cullen, M. McGee-Lennon, S. Brewster, and J. J. Evans, "The efficacy of cognitive prosthetic technology for people with memory impairments: A systematic review and meta-analysis," Neuropsychol. Rehabil., vol. 24, no. 3-4, pp. 419-444, 2014.

[17] B. a Wilson, H. C. Emslie, K. Quirk, and J. J. Evans, "Reducing everyday memory and planning problems by means of a paging system: a randomised control crossover study.," J. Neurol. Neurosurg. Psychiatry, vol. 70, no. 4, pp. 477-82, Apr. 2001.

[18] B. O\&apos;Neill, C. Best, A. Gillespie, and L. O\&apos;Neill, "Automated prompting technologies in rehabilitation and at home," Soc. Care Neurodisability, vol. 4, no. 1, pp. 17-28, 2013.

[19] B. O'Neill, C. Best, L. O'Neill, S. D. S. Ramos, and A. Gillespie, "Efficacy of a Micro-Prompting Technology in Reducing Support Needed by People With Severe Acquired Brain Injury in Activities of Daily Living," J. Head Trauma Rehabil., vol. 33, no. 5, p. 1, 2017.

[20] J. Brown and M. Wollersheim, "Exploring assistive technology use to support cognition in college students with histories of mild traumatic brain injury," Disabil. Rehabil. Assist. Technol., vol. 0, no. 0, pp. 1-12, 2018.

[21] B. J. Fogg, "Using computers to change what we think and do," Persuas. Technol., vol. 5, pp. 89-120, 2003.

[22] M. Brunner, B. Hemsley, L. Togher, and S. Palmer, "Technology and its role in rehabilitation for people with cognitive-communication disability following a traumatic brain injury (TBI)," Brain Inj., vol. 31, no. 8, pp. 1028$1043,2017$.

[23] K. Stawarz, A. L. Cox, and A. Blandford, "Don ' t Forget Your Pill! Designing Effective Medication Reminder Apps That Support Users ’ Daily Routines,” pp. 2269-2278, 2014.

[24] E. J. Topol and D. Hill, The creative destruction of medicine: How the digital revolution will create better health care. New York: Basic Books, 2012.

[25] M. Jamieson and J. J. Evans, "Assistive technology for executive functions.," in in Assistive Technology for Cognition: A Handbook for Clinicians and Developers, B. O’Neill and A. Gillespie, Eds. Psychology Press: UK, 2014.

[26] M. Lennon, L. Baillie, J. Hoonhout, J. Robertson, and G. Fitzpatrick, "Crossing HCI and Health,” Proc. 33rd Annu. ACM Conf. Ext. Abstr. Hum. Factors Comput. Syst. - CHI EA '15, pp. 2353-2356, 2015.

[27] Z. Zador, M. Sperrin, and A. T. King, "Predictors of outcome in traumatic brain injury: New insight using receiver operating curve indices and Bayesian network analysis," PLoS One, vol. 11, no. 7, pp. 1-18, 2016.

[28] T. Hellstrøm, T. Kaufmann, N. Andelic, H. L. Soberg, S. Sigurdardottir, E. Helseth, O. A. Andreassen, and L. T. Westlye, "Predicting Outcome 12 Months after Mild Traumatic Brain Injury in Patients Admitted to a Neurosurgery Service," Front. Neurol., vol. 8, no. April, p. 125, 2017.

[29] M. J. Scherer and S. Federici, "Why people use and don't use technologies: Introduction to the special issue on assistive technologies for cognition/cognitive support technologies," NeuroRehabilitation, vol. 37, no. 3, pp. 315$319,2015$.

[30] N. Bier, J. Sablier, C. Briand, S. Pinard, V. Rialle, S. Giroux, H. Pigot, L. Quillion Dupré, J. Bauchet, E. Monfort, E. Bosshardt, and L. Courbet, "Special issue on technology and neuropsychological rehabilitation: Overview and 
reflections on ways to conduct future studies and support clinical practice," Neuropsychol. Rehabil., vol. 28, no. 5, pp. 864-877, 2018.

[31] J. A. Holton and I. Walsh, Classic grounded theory: Applications with qualitative and quantitative data. Sage, 2016.

[32] F. Rabiee, "Focus-group interview and data analysis," Proc. Nutr. Soc., vol. 63, no. 04, pp. 655-660, Mar. 2007.

[33] J. L. Feuston, C. G. Marshall-Fricker, and A. M. Piper, "The Social Lives of Individuals with Traumatic Brain Injury,” Proc. 2017 CHI Conf. Hum. Factors Comput. Syst. - CHI '17, pp. 182-194, 2017.

[34] M. Jamieson, B. Cullen, M. McGee-Lennon, S. Brewster, and J. Evans, "Technological memory aid use by people with acquired brain injury,” Neuropsychol. Rehabil., vol. 27, no. 6, pp. 919-936, 2017.

[35] A. Mehrotra, M. Musolesi, R. Hendley, and V. Pejovic, "Designing content-driven intelligent notification mechanisms for mobile applications," Proc. 2015 ACM Int. Jt. Conf. Pervasive Ubiquitous Comput. - UbiComp '15, pp. 813-824, 2015.

[36] G. M. Bedell, S. L. Wade, L. S. Turkstra, J. Haarbauer-Krupa, and J. A. King, "Informing design of an app-based coaching intervention to promote social participation of teenagers with traumatic brain injury," Dev. Neurorehabil., vol. 20, no. 7, pp. 408-417, 2017.

[37] Ofcom, "Rise of the Social Seniors revealed," 2018. .

[38] B. van den, "Why does neurorehabilitation fail?," J. Head Trauma Rehabil., vol. 20, no. 5, pp. 464-473, 2005.

[39] N. Alderman, C. Knight, and C. Morgan, "Use of a modified version of the Overt Aggression Scale in the measurement and assessment of aggressive behaviours following brain injury," Brain Inj., vol. 11, no. 7, pp. $503-$ $523,1997$.

[40] B. J. Fogg, "Creating Persuasive Technologies : An Eight-Step Design Process,” 2009.

[41] M. M. Sohlberg and C. A. Mateer, Cognitive rehabilitation: An integrative neuropsychological approach. Guilford Publications: UK, 2017.

[42] T. Hart, T. Tsaousides, J. Zanca, J. Whyte, A. Packel, M. Ferraro, and M. Dijkers, "Toward a theory-driven classification of rehabili-tation treatments," vol. 95, no. 1, pp. 33-44, 2014.

[43] I. Nahum-shani, S. N. Smith, K. Witkiewitz, L. M. Collins, B. Spring, and S. A. Murphy, "Just-in-Time Adaptive Interventions ( JITAIs ): An Organizing Framework for Ongoing Health Behavior Support," vol. 073975, no. 14, pp. $1-37,2014$.

[44] S. I. Lee, C. Adans-Dester, A. O’Brien, G. V. Diaz, R. Black-Schaffer, S. Patel, R. Zafonte, and P. Bonato, "Using Wearable Motion Sensors to Estimate Longitudinal Changes in Movement Quality in Stroke and Traumatic Brain Injury Survivors Undergoing Rehabilitation,” Arch. Phys. Med. Rehabil., vol. 97, no. 10, p. e117, 2016.

[45] S. Kumar, W. J. Nilsen, A. Abernethy, A. Atienza, K. Patrick, M. Pavel, W. T. Riley, A. Shar, B. Spring, D. SpruijtMetz, D. Hedeker, V. Honavar, R. Kravitz, R. Craig Lefebvre, D. C. Mohr, S. A. Murphy, C. Quinn, V. Shusterman, and D. Swendeman, "Mobile health technology evaluation: The mHealth evidence workshop," Am. J. Prev. Med., vol. 45, no. 2, pp. 228-236, 2013.

[46] J. Lin, L. Mamykina, S. Lindtner, G. Delajoux, and H. Strub, "Fish'n'Steps: Encouraging Physical Activity with an Interactive Computer Game," Siemens Corp. Res., pp. 261-278, 2006. 
[47] L. Dennison, L. Morrison, G. Conway, and L. Yardley, "Opportunities and Challenges for Smartphone Applications in Supporting Health Behavior Change," Quali-tative Study. J. Med. Internet Res., vol. 15, no. 4, p. 86, 2013.

[48] M. J. Rotheram-Borus, M. Tomlinson, M. Gwegwe, W. S. Comulada, N. Kaufman, and M. Keim, "Diabetes Buddies: Peer Support Through a Mobile Phone Buddy System,” Diabetes Educ., vol. 38, no. 3, pp. 357-365, 2012.

[49] T. Toscos, A. M. Faber, K. H. Connelly, and A. M. Upoma, "Encouraging Physical Activity in Teens: Can technology help reducte barriers to physical activity in adolescent girls?. Proc. of Pervasive," Proc. Pervasive Heal., vol. 3, no. Group 3, pp. 173-184, 2008.

[50] H. Cole-Lewis and T. Kershaw, "Text messaging as a tool for behavior change in disease prevention and management," Epidemiol. Rev., vol. 32, no. 1, pp. 56-69, 2010.

[51] S. Nundy, J. J. Dick, A. P. Goddu, P. Hogan, C. Y. E. Lu, M. C. Solomon, A. Bussie, M. H. Chin, and M. E. Peek, "Using mobile health to support the chronic care model: Developing an institutional initiative," Int. J. Telemed. Appl., vol. 2012, 2012.

[52] M. Jamieson, M. McGee-Lennon, B. Cullen, S. Brewster, and J. Evans, "Issues influencing the Uptake of Smartphone Reminder apps for People with Acquired Brain Injury," Proc. 17th Int. ACM SIGACCESS Conf. Comput. Access. - ASSETS '15, no. December, pp. 339-340, 2015.

[53] D. K. Davies, S. E. Stock, and M. L. Wehmeyer, "Enhancing Independent Internet Access for Individuals with Mental Retardation through Use of a Specialized Web Browser : A Pilot Study Enhancing Independent Internet Access for Individuals with Mental Retardation through Use of a Specialized Web Browser : A Pilot Study," no. March, 2001.

[54] E. Lopresti, R. Simpson, N. Kirsch, and D. Schreckenghost, "Solo : Interactive Task Guidance,” pp. 190-191, 2005.

[55] E. D. Freeman, L. Clare, N. Savitch, L. Royan, R. Litherland, and M. Lindsay, "Improving website accessibility for people with early-stage dementia : A preliminary investigation Improving website accessibility for people with earlystage dementia : A preliminary investigation," no. October, 2005.

[56] M. G. Friedman and D. N. Bryen, "Web accessibility design recommendations for people with cognitive disabilities," no. November 2015, 2007.

[57] J. Lazar, J. H. Feng, and H. Hochheiser, Research methods in human-computer interaction. Wiley \& Sons: UK, 2010.

[58] R. Hu and J. H. Feng, "Investigating Information Search by People with Cognitive Disabilities," ACM Trans-actions Access. Comput., vol. 7, no. 1, 2015.

[59] E. de Joode, I. Proot, K. Slegers, C. van Heugten, F. Verhey, and M. van Boxtel, "The use of standard calendar software by individuals with acquired brain injury and cognitive complaints: a mixed methods study.," Disabil. Rehabil. Assist. Technol., vol. 7, no. 5, pp. 389-98, Sep. 2012.

[60] M. Jamieson, B. O’Neill, B. Cullen, M. Lennon, S. Brewster, and J. Evans, "ForgetMeNot: Active Reminder Entry Support for Adults with Acquired Brain Injury,” 2017.

[61] P. M. Gollwitzer, "Implementation intentions: Strong effects of simple plans," Am. Psychol., vol. 54, no. 7, p. 493, 1999.

[62] P. M. Gollwitzer and P. Sheeran, "Implementation intentions and goal achievement: A meta-analysis of effects and processes," Adv. Exp. Soc. Psychol., vol. 38, pp. 69-119, 2006. 
Table 1. Type your title Table 1. Details about participant's aetiology (or caregiver's background) and tech literacy.

\begin{tabular}{|c|c|c|}
\hline $\begin{array}{l}\text { Focus group or structured } \\
\text { interview (gender) }\end{array}$ & $\begin{array}{l}\text { Participant Details } \\
\text { (name (names are pseudonyms)[gender, age, } \\
\text { description of technology experience]) }\end{array}$ & $\begin{array}{l}\text { Further details about participants with ABI (if known) } \\
\text { Name (time since injury, current rehabilitation type, marital } \\
\text { status, living status, use of legal illegal substances) }\end{array}$ \\
\hline $\begin{array}{l}\text { 1) } 2 \text { participants with } \mathrm{ABI}- \\
\text { living in the community } \\
\text { ( } 2 \text { male) }\end{array}$ & $\begin{array}{l}\text { Severe ABI - TBI } \\
(\text { Scott }[\text { male, in } 40 \mathrm{~s}]),(\text { George }[\text { male, in } 50 \mathrm{~s}])\end{array}$ & $\begin{array}{l}\text { Scott ( } 3 \text { years since injury), individually delivered community } \\
\text { based rehabilitation, single, living alone, no use of illegal } \\
\text { substances reported by the rehabilitation clinicians). } \\
\text { George ( } 5 \text { years since injury), individually delivered community } \\
\text { based rehabilitation, single, living alone, no use of illegal } \\
\text { substances reported by the rehabilitation clinicians). }\end{array}$ \\
\hline $\begin{array}{l}\text { 2) } 3 \text { Carers of people with } \\
\text { ABI - community care team } \\
\text { ( } 1 \text { female, } 2 \text { male) }\end{array}$ & $\begin{array}{l}\text { All carers of people with ABI - occupational therapist } \\
\text { (Tom [male in } 40 \mathrm{~s}] \text { ); support workers (Jim [male in } \\
40 \mathrm{~s}]) \text {, (Lesley [female in } 30 \mathrm{~s} \text { ). }\end{array}$ & \\
\hline $\begin{array}{l}\text { 3) } 4 \text { people with } \mathrm{ABI}-\text { living } \\
\text { in the community } \\
\text { ( } 2 \text { female, } 2 \text { male) }\end{array}$ & $\begin{array}{l}\text { All mild / moderate ABI - tumour (Fergus [male, in } \\
40 \mathrm{~s} \text { ), fall (Catherine [female in } 30 \mathrm{~s}] \text { ), cardiovascular } \\
\text { accident (Jennifer [female, in } 30 \mathrm{~s}] \text { ), car accident (James } \\
[\text { male, in } 50 \mathrm{~s}]) .\end{array}$ & $\begin{array}{l}\text { Fergus ( } 3 \text { years since injury), group based community based } \\
\text { charity support, marital status unknown, living alone, use of illegal } \\
\text { substances unknown). } \\
\text { Catherine ( } 20 \text { years since injury), group based community based } \\
\text { charity support, not married, living with partner, use of illegal } \\
\text { substances unknown) } \\
\text { Jennifer ( } 1.5 \text { years since injury), group based community based } \\
\text { charity support, married, living with partner, use of illegal } \\
\text { substances unknown) } \\
\text { James ( } 25 \text { years since injury), group based community based } \\
\text { charity support, marital status unknown, living with family, use of } \\
\text { illegal substances unknown) }\end{array}$ \\
\hline $\begin{array}{l}\text { 4) } 3 \text { Carers of people with } \\
\text { ABI - community care team } \\
\text { ( } 2 \text { female, } 1 \text { male) }\end{array}$ & $\begin{array}{l}\text { All carers of people with ABI - occupational therapists } \\
\text { (Scott }[\text { male, in } 40 \mathrm{~s}]),(\text { Stacy }[\text { female, in } 30 \mathrm{~s}]) \text {; clinical } \\
\text { psychologist (Laura [female in } 40 \mathrm{~s}]) .\end{array}$ & \\
\hline $\begin{array}{l}\text { 5) } 4 \text { Carers of people with } \\
\text { ABI - live-in rehabilitation } \\
\text { centre } \\
\text { (4 female) }\end{array}$ & $\begin{array}{l}\text { All carers of people with } \mathrm{ABI} \text { - assistant psychologist } \\
\text { (Amanda [female, in } 20 \mathrm{~s}] \text { ), speech and language } \\
\text { therapist (Cathy [female in } 30 \mathrm{~s}] \text { ); rehabilitation } \\
\text { schedule co-ordinator (Lisa [female, in } 20 \mathrm{~s}] \text { ), } \\
\text { rehabilitation specialist (Audrey [female, in 50s]). }\end{array}$ & \\
\hline
\end{tabular}




\begin{tabular}{|c|c|c|}
\hline $\begin{array}{l}\text { One-to-one session; woman } \\
\text { with ABI living in the } \\
\text { community }\end{array}$ & Severe ABI (TBI) (Sally [female, in 60s]) & $\begin{array}{l}\text { Sally (13 years since injury), group based community based charity } \\
\text { support, married, living with partner, use of illegal substances } \\
\text { unknown). }\end{array}$ \\
\hline $\begin{array}{l}\text { One-to-one session; man } \\
\text { with ABI living in a } \\
\text { rehabilitation centre }\end{array}$ & Severe ABI (TBI) (Mitchell [male, in 40s]) & $\begin{array}{l}\text { Mitchell (10 years since injury), individually delivered inpatient } \\
\text { rehabilitation, single, long term inpatient care, use of illegal } \\
\text { substances unknown). }\end{array}$ \\
\hline $\begin{array}{l}\text { One-to-one session; woman } \\
\text { with ABI living in a } \\
\text { rehabilitation centre }\end{array}$ & Severe ABI (unspecified) (Sophie [female, in 30s]) & $\begin{array}{l}\text { Sophie (6 months since injury), individually delivered inpatient } \\
\text { rehabilitation, single, community living situation was unresolved a } \\
\text { time of interview, use of illegal substances unknown). }\end{array}$ \\
\hline $\begin{array}{l}\text { 6) } 2 \text { Carers of people with } \\
\text { ABI - live-in rehabilitation } \\
\text { centre } \\
\text { ( } 2 \text { female) }\end{array}$ & $\begin{array}{l}\text { All carers of people with ABI - occupational therapists } \\
\text { (Sarah [female, in } 20 \mathrm{~s} \text { ], Jessica [female, in } 30 \text { s]) }\end{array}$ & \\
\hline $\begin{array}{l}\text { 7) Family members of people } \\
\text { with ABI ( } 2 \text { female, } 1 \text { male) }\end{array}$ & $\begin{array}{l}\text { Participants' family members all have severe ABI and } \\
\text { had a spell in a rehabilitation centre (Craig [male, in } \\
60 \mathrm{~s}] \text { ) (Rita [female, in } 40 \mathrm{~s}] \text { ) (Linda [female, in 60s]). }\end{array}$ & \\
\hline
\end{tabular}


Table 2. Outline of the barriers to the performance of meaningful activities for people with ABI

\begin{tabular}{|c|c|}
\hline Master Themes & $\begin{array}{l}\text { Sub Themes } \\
\text { number of comments from participants - (total) (clinicians/service } \\
\text { users). }\end{array}$ \\
\hline Access & $\begin{array}{l}\text { Physical disabilities (15) }(9 / 6) \\
\text { Accessing activities (18) }(12 / 6) \\
\text { Accessing solutions }(37)(16 / 21)\end{array}$ \\
\hline Cognition & $\begin{array}{l}\text { Memory }(11)(8 / 3) \\
\text { Executive function / planning }(21)(12 / 9) \\
\text { Social cognition } 11(5 / 6)\end{array}$ \\
\hline Anticipation of difficulties & $\begin{array}{l}\text { Due to physical disability } 5(0 / 5) \\
\text { Due to cognitive difficulties } 8(5 / 3)\end{array}$ \\
\hline Motivation & $\begin{array}{l}\text { Mental health } 10(9 / 1) \\
\text { Pre-morbid lifestyle } 8(8 / 0) \\
\text { Losing momentum } 14(7 / 7)\end{array}$ \\
\hline
\end{tabular}


Table 3. Outline of the solutions that can overcome the barriers to the performance of meaningful activities for people with ABI

\begin{tabular}{|c|c|}
\hline Master Themes & $\begin{array}{l}\text { Sub Themes } \\
\text { number of comments from participants - (total) (clinicians/service users). }\end{array}$ \\
\hline $\begin{array}{l}\text { External prompting / } \\
\text { motivation }\end{array}$ & $\begin{array}{l}\text { From other people (41) (25/16) } \\
\text { From technology } 21(14 / 7)\end{array}$ \\
\hline Maintaining & Repetition / habit $8(8 / 0)$ \\
\hline Momentum & Encouragement 10(10/0) \\
\hline Being planful & $\begin{array}{l}\text { Specific plans }(22)(17 / 5) \\
\text { Memory strategies }(13)(8 / 5) \\
\text { Collaborative plans } 5(5 / 0)\end{array}$ \\
\hline Problem / Solution cycle & $\begin{array}{l}\text { Solutions that hinder as well as help } \\
(5)(5 / 0) \\
\text { Perceived solution not working } \\
(11)(9 / 2)\end{array}$ \\
\hline
\end{tabular}


Table 4. A summary of the areas of focus for assistive technology development that would help to overcome the barriers, and facilitate the solutions, described by participants in this study.

\begin{tabular}{|c|c|c|}
\hline $\begin{array}{l}\text { Assistive Technology } \\
\text { Focus }\end{array}$ & Barriers this can overcome & Solutions provided \\
\hline Social & $\begin{array}{l}\text { Motivation } \\
\text { Accessing activities } \\
\text { Anticipation of difficulties }\end{array}$ & $\begin{array}{l}\text { External motivation } \\
\text { Specific plans /logistics } \\
\text { Collaborative plans }\end{array}$ \\
\hline Persuasive & $\begin{array}{l}\text { Pre-morbid lifestyle } \\
\text { Anticipation of difficulties } \\
\text { Losing momentum }\end{array}$ & $\begin{array}{l}\text { Idea generation } \\
\text { Internal motivation } \\
\text { Repetition / habit }\end{array}$ \\
\hline Personal & $\begin{array}{l}\text { Physical disability } \\
\text { Cognitive difficulties } \\
\text { Problem / solution cycle }\end{array}$ & $\begin{array}{l}\text { Personalised plans } \\
\text { Memory strategies } \\
\text { Personalised features }\end{array}$ \\
\hline Planning & $\begin{array}{l}\text { Executive function / planning } \\
\text { Memory difficulties } \\
\text { Losing momentum }\end{array}$ & $\begin{array}{l}\text { Specific plans } \\
\text { Memory strategies } \\
\text { Repetition/habit formation }\end{array}$ \\
\hline
\end{tabular}

